\title{
University engagement through local food enterprise: community-supported agriculture on campus
}

\section{Authors: Christopher Wharton and Alison H. Harmon}

This is an Accepted Manuscript of an article published in Journal of Hunger \& Environmental Nutrition on May 21, 2009, available online: http://www.tandfonline.com/10.1080/19320240902915235.

Wharton, Christopher, and Alison H. Harmon. "University Engagement Through Local Food Enterprise: Community-Supported Agriculture on Campus." Journal of Hunger \& Environmental Nutrition 4, no. 2 (May 21, 2009): 112-128. doi:10.1080/19320240902915235.

Made available through Montana State University's $\underline{\text { ScholarWorks }}$ scholarworks.montana.edu 


\title{
PERSPECTIVES
}

\section{University Engagement Through Local Food Enterprise: Community-Supported Agriculture on Campus}

\author{
CHRISTOPHER WHARTON $^{1}$ and ALISON HARMON ${ }^{2}$ \\ ${ }^{1}$ Department of Nutrition, Arizona State University, Mesa, Arizona, USA \\ ${ }^{2}$ Department of Health and Human Development, Montana State University, \\ Bozeman, Montana, USA
}

\begin{abstract}
Community-supported agriculture programs (CSAs) are growing in number and variety across the country. Though CSAs can be found in a variety of settings, a less common but potentially successful venue in which to run a CSA is the university campus. Although universities present certain challenges for operating a CSA, they offer a number of unique advantages that can aid in the growth and success of the campus CSA. As such, university-based food and nutrition professionals may find that CSA development is a viable avenue through which to accomplish nutrition goals, such as increasing consumption of fresh fruits and vegetables. In this article, the authors review both the benefits and detriments of operating a CSA on a university campus and present 2 different but successful university CSA models.
\end{abstract}

KEYWORDS community-supported agriculture, local foods, university garden, university farm, campus CSA

\section{INTRODUCTION}

In recent years, community-supported agriculture (CSA) programs have emerged as an increasingly popular source of locally grown produce,

Address correspondence to Christopher Wharton, Department of Nutrition, Arizona State University, 6950 E. Williams Field Rd., Mesa, AZ 85212. E-mail: christopher.wharton@asu.edu 
animal products, and processed consumer goods. The CSA movement originated in Europe and Japan and made its way to the United States in the 1980s. ${ }^{1}$ Despite the short duration of their existence in the United States, CSAs have quickly filled a local and sustainable food niche. In the last decade, the number of CSA farms has gone from an estimated 600 across North America to well over 2000 today in the United States alone.,3

Establishment of, and participation in, CSAs has grown at an even greater rate in recent years due to popular interest in alternatives to the industrialized food system. Journalists, advocates, and scientists alike have discussed the benefits and detriments inherent in the current food system, and they have popularized the ideals and potential benefits of alternative sources of food like CSAs. ${ }^{4}$ Primary among these ideals are commitments to the local community and its farmers and protection of the environment through consumption of local foods. ${ }^{5}$ For example, in a CSA program, consumers pay up front for a certain number of regular allotments, or shares, of produce grown by local farmers. Farmers commit to providing produce to their CSA members and use the membership fees as capital to run or initiate annual farm operations. CSAs thus provide a mechanism for community members to support their local farmers while keeping their money circulating in the local economy. At the same time, CSA members perceive an environmental benefit from participation. Farmers or members generally travel a much shorter distance to deliver or retrieve their produce than do foods typically found in grocery stores. Also, production on CSA farms often employs organic, low-input agricultural methods; acreages are typically small and crops are diversified. ${ }^{6}$

A number of reasons might explain the growing memberships of CSAs. Several researchers have assessed motivations for involvement in CSAs and subsequent literature consistently identifies the quality of produce (both freshness and nutritional value), food safety, cost and convenience, and social connectivity to be of great importance. ${ }^{1,5,7}$ In fact, attitudinal variables such as the desire to support local enterprise, community attachment, and concern for the environment appear to be more important predictors of CSA membership and satisfaction than are more traditional predictors of foodrelated behaviors like education or income..$^{7-9}$

CSAs also offer a number of community-related and health-related benefits. CSAs can play an important role in the communities in which they exist by providing a venue for socially just food interactions. For example, the farmer receives a fair wage ahead of the season, which prevents the accumulation of debt; shares the economic risks associated with agricultural production; and has an opportunity to know his or her customers personally. By paying ahead for a share of the harvest, members literally invest in the local landscape and the variety of foods it can seasonally provide. In sharing risk, members subordinate their own economic interests to support a particular CSA farmer and farm. ${ }^{10}$ 
In exchange for the price of a share, members receive whole, fresh, high-quality, nutrient-dense produce in a fashion that contributes to good health directly by increasing consumption of fruits and vegetables and indirectly by encouraging healthful eating behaviors and minimizing detractions. Increased servings of fresh produce, especially dark green vegetables, might displace servings of less healthful foods. Studies have found that members increase their intakes of fiber and vitamin A and decrease intake of saturated fat. ${ }^{11,12}$ Additionally, a CSA membership can decrease the number of food shopping trips to more conventional venues such as the supermarket, thus decreasing the number of opportunities to purchase less healthful foods on impulse and saving money. Researchers have demonstrated that fresh produce purchased through a CSA program is less expensive than the equivalent amount of produce purchased at a supermarket, regardless of whether the supermarket produce is grown using organic or conventional methods. ${ }^{1}$

Of particular importance to food and nutrition professionals is the role that CSAs can potentially play in enhancing health and well-being on individual, family, and community levels. The possibility of personal transformation exists for CSA members. ${ }^{13}$ Hypothetically, CSA membership allows members to deepen their relationship and involvement with food while providing a vehicle for social interactions. For example, members often have the opportunity to visit the farm where their food is being grown and thus the opportunity to know the source of their food and the person or people who produced it. ${ }^{1}$ Retrieving a weekly share often involves slowing down what might otherwise be a faster paced relationship with food, in which people tend to minimize the time they spend obtaining, preparing, and consuming food. Additional time is needed to prepare a weekly share for storage (ie, thorough washing, removing the occasional caterpillar, trimming greens, peeling, slicing, etc) than if produce is purchased prewashed and sliced in a package. Because all produce is fresh, additional time is spent cooking or preparing meals than would be spent heating or reheating packaged convenience foods. Consequently, the process of incorporating a weekly share into a variety of meals can provide meaningful culinary experiences for members. CSA shares can include less familiar and less common vegetables with which members may have little prior experience. ${ }^{14} \mathrm{~A}$ family is more likely to spend time together eating a meal that requires more effort to prepare. The quantity of food supplied by a weekly share is often in excess of what members can reasonably use, providing another valuable opportunity to share food with friends and neighbors or to experiment with the art of composting.

Food production through CSAs also makes a contribution to the local food supply and community food security. Prior work has detailed the many ways that CSAs can contribute to emergency food system efforts in communities and to government-sponsored nutrition assistance programs. CSAs can partner with food banks as well as food stamps, school lunch, and WIC farmers market nutrition programs. ${ }^{15,16}$ 
Because of the many benefits they offer communities and individuals, CSAs can and do succeed in a variety of settings. Although little has been written about the types of venues available for CSAs, one place in which CSAs can prosper is a college or university campus. ${ }^{17-20}$ School campuses offer access to a variety of populations; have a number of built-in systems to facilitate communication and access to a CSA; and can offer meaningful experiences for students, staff, faculty, and community members alike. Like any venue, campuses also present certain disadvantages or unique barriers. This article first describes the benefits and barriers of operating a CSA on a college or university campus, based on the experiences of the authors. Then the article describes 2 models that provide examples of the ways a CSA can offer opportunities, and fresh produce, to the various communities interacting in university settings. The descriptions should help food and nutrition professionals affiliated with colleges or universities initiate and/or collaborate on a CSA project.

\section{CSAS IN UNIVERSITY SETTINGS: BENEFITS AND BARRIERS}

An alternative food distribution model - the CSA-provides an excellent venue through which to engage community members in a local food system. Whether using university land to establish a farm and run a CSA or working with a non-university-related local farmer, universities offer ideal settings for CSA involvement and can provide numerous benefits to CSA stakeholders. What follows is a review of proposed benefits, and consideration of barriers, to CSA operations in the university setting.

\section{BENEFITS}

\section{Engaging the Community}

Universities often include in their missions the goal of remaining socially engaged, and a campus CSA provides ample opportunities to do so by involving both university constituents and community stakeholders in the production, procurement, and delivery of fresh produce to a variety of communities. Students, staff, faculty, and non-university-affiliated community members from surrounding areas can all be involved. Members of each of these communities can participate in the CSA itself and interact with individuals they might not otherwise have met. For students, staff, and faculty, the campus CSA is a convenient location to pick up produce given that they travel to and around campus most days of the week to attend classes or for work. Quite often, the college or university is embedded within a larger town or city. As such, community members living in the area have access to the CSA as well. CSAs can also reach beyond their participating members. When CSAs are left with excess produce, they may make donations to area 
food banks. This increases the number of individuals receiving fresh, nutritious produce from the CSA and aids in advancing universities' missions of serving their surrounding communities as well as their students.

Campus CSAs can also provide food to the university through development of occasional or enduring collaborations with university food service operations. University catering can use donated or purchased CSA produce for particular events or university foodservice can use CSA produce on an ongoing basis in student residence hall meals. Utilizing CSA produce for nonrecurring activities generally requires one-time agreements between the food service company and the CSA. Consistent provision of produce for food service dining hall use, however, will likely require a more detailed agreement as well as other documentation. If the farm operation is distinct from the university, proof of liability insurance would be required from the farm operation, or the farm may need to work through the distributor from which the food service regularly receives orders. With the growing interest in the "greening" of universities, however, these processes are becoming more streamlined. ${ }^{21}$

\section{Using CSA Revenue}

The university setting also offers unique opportunities for program funding and for use of CSA-generated funds. Funds might be used, for instance, to improve the CSA program and broaden its reach to include more community members. This can include development and maintenance of a Web site, creation and printing of advertisements, purchase of equipment and materials to more effectively or efficiently operate the CSA, or offering reduced membership fees for limited-resource students or families. Funds might also be used to pay for speaking engagements, documentary movie events, cooking demonstrations, or other one-time programs that educate community members about local foods and sustainable agriculture. Using CSA produce at these events for catering will create a unique, local foods theme and bring more attention to the CSA itself.

Depending on its size and revenues generated, the CSA might also hire paid student interns. Or, a cooperative agreement can be established between the CSA and the farm that grows its produce. CSA revenue can be used to pay interns to work on the farm and simultaneously earn academic credits. Alternatively, student helpers may donate time to help run the CSA in return for a share of CSA produce.

\section{Utilizing the University Infrastructure}

The university infrastructure offers a set of major advantages for campus CSAs. In particular, the university CSA can take advantage of already existing communication systems and well-networked communities. Universities usually maintain E-mail lists, listservs, electronic and print newsletters, 
campus billboards, and university-run newspapers, all of which can promote participation in the campus CSA. These communication systems reach a large number of individuals with frequency. Many of these routes of communication may be free to use for the CSA coordinator or may come at a much-reduced cost compared to traditional print or electronic advertising. Also, because many different communities are well connected through regular interaction on campus, word-of-mouth is also a powerful way to advertise the CSA. This form of communication has been shown to be of great importance in getting the word out about local foods programs. ${ }^{5}$

Similarly, universities (especially those with larger or multiple campuses) often maintain coordinated transportation systems, which potential CSA shareholders can use to reach pickup locations. Most often, mass transit systems such as buses will be available. Universities might also have alternative transportation for students and employees who live on campus. Some universities, such as Arizona State University, offer bicycle co-ops or hourly car rentals that university community members use for free or at a minimal price. $^{22,23}$ These systems not only allow CSA members to traverse a single campus, they might also allow for easy transportation between the university CSA pickup location and home. Together, the various university transportation options can make a CSA that might seem too far away otherwise accessible.

\section{BARRIERS}

\section{Working Within University Regulations}

The university-based CSA, despite its many advantages, does suffer from various potential barriers. Most consistent among these are issues of liability and food service contractual obligations. Universities, much like any large institution, have strict food quality and safety standards. As such, any food-related program operated on the university campus must also comply with university rules and regulations surrounding provision of foods. Regulations cover everything from the water used to grow produce sold through the CSA to the time and location where the CSA distribution occurs. CSAs that obtain their produce from off-campus farms often must provide proof of a certain level and type of liability insurance to both the university and its contracted food service. Similarly, CSA coordinators might occasionally be required to negotiate sales of shares as well as distribution locations with university food service organizations. Sales or distribution of shares near or at food service locations on campus may compete with the food service, and this generally is contractually disallowed. Importantly, maintaining good relationships with university officials and food service personnel will aid in working through these issues. And, because many universities already recognize the importance of sourcing at least some 
food locally, there could already be systems in place to cooperate with local producers.

\section{Dealing with Logistics}

Barriers also exist in terms of basic logistics, both for shareholders and for CSA coordinators. Students and faculty must contend with widely variable class schedules and outside class commitments that sometimes make establishing a weekly share pickup time and location quite difficult. Students in particular might also lack the facilities and cooking equipment to use all produce within a share, especially those students living in dormitories. Finally, students, university employees, and other participating community members often are working within tight budgets, making it harder to consistently participate in a CSA. To contend with these issues, the CSA coordinator should provide lists of other members who might be willing to split shares with students or university employees. With a split share, a member literally splits his or her share in half with another member. In this case, the 2 members work out a schedule for pickup, covering for each other when schedules get busy. The share can also be split in terms of who can best use each item (one member might have access to cooking facilities when another does not, for instance). A split share also means that each member pays only half the price, easing the potential financial burden.

Other strategies to deal with barriers that members face include providing payment plans and newsletters with simple recipes. CSA payment plans allow for individuals to pay for their shares in installments. This strategy can greatly increase participation in CSAs for individuals who find it difficult to pay a larger lump sum up front. Often, university employees pay for university services such as a gym membership or parking fee through payroll deduction. Paying for a CSA share could be arranged in a similar way. Newsletters that include recipes requiring only minimal preparation and cooking — or no cooking at all—will also make it easier for students or members who do not consistently cook to use the produce within their share.

\section{CSAS ON UNIVERSITY CAMPUSES: TWO CASE STUDIES}

\section{Towne's Harvest Garden: A Student-Initiated CSA}

Towne's Harvest Garden (THG) is a 2-acre vegetable garden on Montana State University's (MSU's) agricultural research and teaching farm. MSU Friends of Local Foods, a student organization, formed in the fall of 2006 and began operating the CSA the following summer. Students launched this project with considerable financial support (approximately \$10 000) from university administrators in 2 colleges (Agriculture; and Education, Health 
and Human Development), greenhouse space and resources from the College of Agriculture, and a land and water allowance from the Montana Agricultural Experiment Station. Additional financial support was provided by the Gallatin Valley Food Bank through the initial purchase of 25 CSA shares. Other support for THG initiation came from small grants offered by community organizations and a 5-a-Day grant offered by the Montana Nutrition and Physical Activity Program.

The Mission of Towne's Harvest is to be a source of "locally, sustainably, and educationally grown food" for the campus and members of the surrounding community. THG strives to be a permanent part of MSU, a dynamic working model of sustainable production on a small-scale market farm, an outdoor classroom and research laboratory for related coursework and inquiry, a source of inspiration for current and prospective students from diverse backgrounds to become involved in local and alternative food systems, and a force for increasing access to fresh nutritious produce and community food security through food bank partnerships.

\section{LOGISTICS}

Towne's Harvest is located approximately one mile from the center of MSU's main campus in Bozeman. Produce is distributed to CSA members on a weekly basis starting in mid-June and continuing through mid-September. Weekly shares are picked up by members at the garden location between the hours of 4-6 Pм. The market-style distribution allows members to assemble their own share by reading signs indicating the maximum quantity (count or weight) of each item allowed per share. The weekly produce allotment is highly dependent on production success and the particular week of the season. Share weight varies between 3 and 15 pounds depending upon what produce is available (eg, salad greens vs potatoes).

\section{MEMBERSHIPS}

New members purchase their shares in March; returning members, however, have the opportunity to purchase their shares one month earlier as a benefit of previous involvement. As a result, returning members avoid being placed on a waiting list, which often develops given the limited number of shares available. Minimal advertising is needed because the university setting allows for effective word-of-mouth communication about the project, but organizers distribute brochures describing the CSA, its associated costs, and procedures for joining. Additionally, information is also available on the Towne's Harvest Garden Web site. ${ }^{24}$ Prospective members complete an application form, sign a university lawyer-approved contract, and submit payment to the campus mailbox of MSU Friends of Local Foods. In 2007, 40 memberships were available; in 2008 the number increased to 55. 
In both cases, shares were sold out by the end of April, and additional prospective members were referred to other CSAs in the area. Montana State University does not wish to compete with small-scale farm operators in the region, so share prices for Towne's Harvest are purposely set higher than those of other CSAs. In 2007 a 13-week membership was \$400. In 2008 a 14 -week membership cost members $\$ 425$. All members paid their membership fee by check, in advance of the season. To date, no alternative payment methods or schedules have been arranged for members. At least one request has been made for payment through university payroll deduction and is worthy of exploration. Organizers are currently seeking grants to offer lower cost limited-resource shares.

\section{OPERATIONS}

To operate Towne's Harvest in 2007, MSU Friends of Local Foods developed a job application and hired 4 student interns ( 2 full-time farm interns and 2 part-time food educators). Farm interns were chiefly responsible for production activities, and food educators were responsible for outreach, education, distribution, and marketing but also helped with production activities as needed. Very little outreach was conducted the first season due to the continuous need for production labor. In all, the first season required approximately 3000 paid hours in addition to almost 800 volunteer hours. Early in the season, harvesting occurred only on distribution day to ensure that members received the freshest possible produce. Later in the season, produce was harvested twice weekly, with the second harvest primarily going to the food bank. Other than transplanting, planting, and harvesting, continuous weeding is the activity requiring the most labor.

In the 2008 season, faculty advisors revised the organizational structure by hiring a coordinator to manage and oversee student interns. Improved supervision and communication were the goals of this change. Additionally, 3 full-time interns were hired ( 2 full-time farm interns and 1 full-time marketing and outreach intern). Produce was distributed to the food bank on Monday and to members either on Tuesday or Friday. Thus, in the second season, produce was harvested 3 times per week, leaving 2 days for planting and weeding activities.

The amount and type of produce distributed each week varies seasonally. Early in the season, members receive salad greens, radishes, spinach, green onions, arugula, broccoli, chard, and basil. In July, a share might include kale, carrots, peas, summer squash, eggplant, and fennel. In August, green beans, cabbage, cauliflower, tomatoes, peppers, beets, kohlrabi, corn, and cucumbers become available. At the end of the season, members enjoy melons, leeks, squash, potatoes, and onions. Cut flowers are offered to members whenever available. 


\section{TEACHING AND OUTREACH}

The Towne's Harvest Web site is linked to that of Montana State University. ${ }^{24}$ Visitors to the site can learn about the history of Towne's Harvest, download an annual report, see photographs, find information about visiting and volunteering, download CSA membership brochures and applications, download recent popular media articles about the project, download current or archived newsletters, and read about Towne's Harvest job and internship opportunities. A weekly newsletter provides a list of vegetables in the current CSA share, basic storage and preparation guidance, a featured recipe, notes from the field, a biography of someone closely associated with the project (interns, advisors, and volunteers are highlighted), and announcements about upcoming Towne's Harvest events.

In an effort to build community, CSA members are invited to a preseason orientation at the garden where they receive general information about the project as well as specific instructions related to the weekly distribution of produce. Additionally, members are invited to periodic potlucks at the farm, a field day with speakers and a tour of the garden, and the annual harvest festival, which is held at the end of the season and is open to the general public as well.

Awareness about Towne's Harvest is built in a number of ways. Primarily, the program disseminates brochures about CSA membership. The CSA coordinator and faculty advisors also issue press releases, interviews with newspaper reporters, and participate in short radio and television spots on local news programs. The project makes a weekly appearance at a local farmers' market where information is distributed and surplus produce is sold along with promotional items bearing the Towne's Harvest logo.

Individuals or groups who wish to volunteer are welcome to visit Towne's Harvest at designated volunteer times during the week or by appointment. Visits are coordinated by the marketing and outreach intern. Likewise, families, clubs, or organizations are encouraged to visit the farm during designated hours or by appointment to take a tour.

Part of the vision for Towne's Harvest is that it be a place of learning about local food for the community and an outdoor classroom and research laboratory for the university. Several MSU faculty have brought students to the garden for tours or to teach specific concepts. Specific courses have been more integral to the planning and operation of the garden. For example, graphic design students were given the opportunity to design the project logo in a contest. The winner was awarded a CSA membership. Students in a culinary management course developed recipes for university catering featuring local foods to encourage integration of university foodservices and the Towne's Harvest project. Community nutrition students designed a cookbook specifically for CSA members with recipes and nutrition information featuring produce grown at Towne's Harvest. Students in a 
land resources and environmental science course developed the initial layout for the garden, determining how many rows of each crop should be planted to achieve the needed vegetable harvest. Additional faculty have offered students in various courses service learning credit for volunteering at the garden.

Students have the opportunity to apply for paid internships on the farm. Employees must be enrolled in summer courses such as Organic Market Gardening or Culinary Marketing: Farm to Table-both taught at the garden site-or internships, independent studies, or research.

The Gallatin Valley Food Bank has been an integral part of the initiation and continued development of the THG project. Partnership with the food bank began with its purchase of 25 CSA shares in the first season. In exchange, food bank clients were provided with approximately 6000 pounds of fresh produce. The partnership continued in much the same way over the 2008 season, except THG made more effort to provide the food bank with the specific produce items desired by clients rather than simply expanded portions of the more typically varied share. The partnership will continue to evolve in order to better meet food bank needs. Additionally, the food bank has purchased land adjacent to its warehouse so that some produce can be grown for clients on-site, with the help of the many volunteers attracted to service at that location. Working with the Gallatin Valley Food Bank is consistent with the university's mission "To serve the people and communities of Montana by sharing our expertise and collaborating with others to improve the lives and prosperity of Montanans." 25

\section{ONGOING GOALS}

Goals of Towne's Harvest include achieving the optimal organizational structure and balancing internship opportunities with labor needs, production expectations, and the capacity of the project to generate adequate revenue through CSA memberships and produce sales at the farmers market. Becoming a fiscally self-reliant operation that can support its own basic operations is also critical, where external or internal administrative funds are sought only for project development and infrastructure improvement. Further integration with university curricula will include splitting CSA coordination duties between 2 qualified graduate assistants who will then each focus on one aspect of the project in master's thesis or project work. Further collaboration with university food service will include a composting project and the market-style distribution of fresh produce on campus as well as the provision of university-grown items for special residence hall meals, catered events, and student union eateries. Finally, part of the vision for the project is to increase access to fresh, locally produced nutritious food. Partnership with the Gallatin Valley Food Bank will likely expand, as will the ability to offer lower cost shares to limited-resource families. 


\section{PolyHarvest: A Faculty-Administered CSA}

The PolyHarvest CSA began in January of 2008 at the Polytechnic campus of Arizona State University (ASU). The first author initiated this program with volunteer help from 2 undergraduate students. PolyHarvest began modestly as a service activity for the university and surrounding communities. As such, no budget existed for its initiation, personnel, or advertisement. Through an agreement with a local CSA farm, the program provides the delivery of fresh produce to a central location on campus where shareholders come once a week to pick up their shares.

The original impetus for the development of a CSA on the college campus came from a group of faculty interested in issues of sustainability. Members of the group focused on food as an important and broad-ranging issue. They decided that a CSA on campus would simultaneously provide community support for local agriculture while developing and displaying a model for sustainable food practices. As such, PolyHarvest came to exist with the goals of providing fresh, local produce to community members as well as making students aware of alternative food sources.

\section{LOGISTICS}

Given the climate in Arizona, the PolyHarvest CSA runs continuously throughout the year. The program distributes produce weekly out of the student union on the Polytechnic campus of ASU. The CSA remains open for 2 hours, between 4:45 and 6:45 PM each Thursday, to provide a chance for individuals to pick up their produce during after-work hours. Members must bring their own totes or boxes to the pickup location, where they may choose their own produce from bins provided by the farm. The allotment of produce is based not on poundage but number of items. Members generally receive 8 items each week, although a single item might be one melon, 2 grapefruit, or multiple potatoes, for example. Members also have the option to trade out items they might not want. The CSA provides an extra trading share for this purpose, which includes each of the 8 weekly items.

\section{MEMBERSHIP}

PolyHarvest memberships are offered 4 times a year, although interested individuals can opt to join at any time. Memberships are based on 12-week "seasons" and members generally pay for their membership up front. However, given a growing involvement by undergraduate and graduate students, a number of payment options were recently introduced. The cost for a full 12 -week season is $\$ 240$, or $\$ 20$ per week. However, for those who have difficulty paying entirely up front, the CSA offers 2-payment and 3-payment plans. Also, for those who feel uneasy about committing to 
12 weeks of shipments, a 6-week membership option is provided. Those who join with a 6-week membership pay a slightly higher price per week than those committing to 12 weeks; 6-week members pay $\$ 150$ up front, or $\$ 25$ per week. However, if these members decide to continue receiving produce for the second 6-week period of the 12-week season, they pay only $\$ 90$ more, and therefore pay a total of $\$ 240$. Individuals who wish to join later in the season may do so, but they must pay in full up front.

All members must sign a contract that commits them to their payment plan. Information about the CSA, pickup procedures and location, and the importance of supporting local farmers through such programs is provided in the contract and must be read prior to signing. Generally, potential members learn about the CSA through word-of-mouth on campus or through flyers and electronic announcements posted across campus. They then contact the faculty coordinator for a contract, which is distributed through E-mail or provided through the CSA Web site. ${ }^{27}$

PolyHarvest members have benefited from the well-developed transportation system offered across and among all 4 ASU campuses. Intercampus shuttles are used widely by students, staff, and faculty, and a number of CSA members come from other campuses or the surrounding community. As such, where the reach of a conventional CSA might be limited based on the public transportation system surrounding its location, the PolyHarvest CSA remains widely accessible through the well-established transportation system already well known to community members.

\section{OPERATIONS}

The responsibility for operating the CSA remains with the original faculty coordinator. However, interested students occasionally provide volunteer help throughout the academic year. Thus far, volunteer help has come from one graduate student in the Nutrition Department at the Polytechnic campus and one undergraduate interested in fulfilling service hours for a nutrition course. Volunteers contributed about 100 total hours over the course of 5 months, primarily in developing the CSA newsletter and identifying recipes to distribute to members. Students also helped advertise the CSA by posting flyers, tabling at campus-wide events, and posting electronic announcements through university communications systems.

Because growing seasons run year-round, members enjoy a wide variety of produce, depending on the time of year. During the "cool season," root vegetables and greens dominate, including beets, radishes, carrots, kale, spinach, and mixed greens. Members also can expect sweet potatoes, winter squash, pumpkins, and peas. ${ }^{26}$ During the "warm season," shares include tomatoes, eggplant, onions, zucchini, melons, and red potatoes. ${ }^{25}$

A coordinator operates the CSA and produce comes from an off-site farm, thus full-time or part-time paid positions are not required. As such, the 
small amount of revenue generated through the CSA is used to offer at least 3 events each semester. The CSA has collaborated with ASU's foodservice company, Aramark, to cater speaker events and movie showings. Additionally, the program has sponsored a cooking demonstration using its produce and chefs from a local restaurant.

\section{OUTREACH}

PolyHarvest maintains a Web site independent of the university. ${ }^{27}$ Although a Web site could have been built using space allotted to the faculty coordinator freely through the university, this was avoided for a number of reasons. Primarily, use of university Web space would have required reference to both the university as well as the primary author in the Web address itself. These uniform resource locator (URL) requirements would result in an overly long Web address that would be difficult to distribute and difficult for potential members to remember. Also, because the site is not associated with the university, community members who hear of the CSA but are otherwise not affiliated with the university might feel more welcome and consider joining the program. The Web site includes a description of the CSA model, details of the PolyHarvest program, and pictures of CSAsponsored events. Visitors can also find old newsletters as well as membersubmitted recipes. Newsletters are published and delivered weekly to CSA members via E-mail and include the week's share list, recipes, and information on a "veggie of the week."

Advertisement for the program is limited given the availability of volunteers and the faculty coordinator. However, the little advertising conducted thus far has been remarkably effective, to a great extent by taking advantage of electronic communications systems maintained by the university. Word-of-mouth, however, seems to have been the most effective means of recruiting new members each season.

As of yet, the PolyHarvest program is not integrated in the university curriculum. However, individual students are utilizing the program to fulfill some course requirements. One nutrition undergraduate used the program to fulfill a 72-hour service requirement for a course. Another group of undergraduate students used the program to fulfill a requirement to develop a marketing scheme for a local business. They developed a marketing analysis plan and compared the CSA to surrounding local foods programs for their final class project.

The PolyHarvest CSA has begun the work of social engagement as well. The program donates its occasional excess produce to an on-campus organization that provides transitional housing to homeless individuals. This organization takes food donations but rarely receives fresh produce as part of those donations. PolyHarvest thus is one of the few sources of fresh fruits and vegetables for individuals taking advantage of this service. 


\section{ONGOING GOALS}

The program remains a volunteer activity for participating faculty and students. Even so, the hope of the coordinator is to increase the visibility of the program such that it can be used by more students for class projects, service hours, volunteer requirements, and other activities. Ideally, student clubs, such as the campus's student nutrition council and a recently developed sustainability club, will recognize PolyHarvest as an opportunity to promote their messages and run associated events.

\section{CONCLUSION}

With the growth of popular and academic interest in the local foods movement, local food programs like CSAs represent a useful alternative source of produce for communities in many settings, including universities. Food and nutrition professionals can take advantage of local food programs on campus in a variety of ways. The campus CSA meets university goals of social engagement; provides educational and other opportunities for students, staff, and faculty alike; increases access to nutritious, whole foods for many communities; and connects communities with their food and the farmers who produce it. Given the advantages of the university setting, the campus CSA has a greater chance of success in reaching a variety of communities and remaining financially viable.

The body of research on local foods programs currently is small; thus, a number of venues exist through which to study the effects of involvement in CSAs and other similar programs. Of particular interest is the effect that campus-based CSAs might have on health, through the modification of attitudes, food skills, and eating behaviors of participating members, especially students. Because universities increasingly recognize student interest in local foods, ${ }^{28}$ the attitudes of administrators toward the campus CSA could also be of interest. Finally, the CSA's efficiency in meeting the needs of its various members might be of interest to program evaluators interested in local foods.

\section{REFERENCES}

1. Cooley JP, Lass DA. Consumer benefits from community supported agriculture membership. Rev Agric Econ. 1998;20:227-237.

2. Klausner A. Sharecropping has newfound cachet as community supported agriculture. Environ Nutr. 1996;19:1,6.

3. Local Harvest. Community supported agriculture. Available at: http://www. localharvest.org/csa/. Accessed November 18, 2008. 
4. Hamilton ND. Farmers' markets rules, regulations, and opportunities. Available at: http://www.nationalaglawcenter.org/assets/articles/hamilton_farmersmarkets.pdf. Accessed December 20, 2008.

5. Brehm JM, Eisenhauer BW. Motivations for participating in community supported agriculture and their relationship with community attachment and social capital. South Rural Sociol. 2008;23:94-115.

6. Wells BL, Gradwell S. Gender and resource management: community supported agriculture as caring-practice. Agric Human Values. 2001;18:107-119.

7. Kolodinsky JM, Pelch LL. Factors influencing the decision to join a community supported agriculture (CSA) farm. J Sustain Agric. 1997;10:129-141.

8. Zepeda L. Who buys local food? J Food Distrib Res. 2006;37:1-11.

9. Lang KB. Expanding our understanding of community supported agriculture (CSA): an examination of member satisfaction. J Sustain Agric. 2005;26:61-79.

10. Hinrichs CC. Embeddedness and local food systems: notes on two types of direct agricultural marketing. J Rural Stud. 2000;16:295-303.

11. Cooley J. Community Supported Agriculture: A Study of Shareholders' Dietary Patterns, Food Practices, and Perceptions of Farm Membership [master's thesis]. Amherst, Mass: University of Massachusetts; 1996.

12. McCullum C. Using sustainable agriculture to improve human nutrition and health. J Community Nutr. 2004;6:18-25.

13. Ostrom MR. Community supported agriculture as an agent of change. In: Hinrichs CC, Lyson TA, eds. Remaking the North American Food System: Strategies for Sustainability. Lincoln, Neb: University of Nebraska Press; 2007:99-120.

14. Andreatta S, Rhyne M, Dery N. Lessons learned from advocating CSAs for low-income and food insecure households. South Rural Soc. 2008;23:116-148.

15. Forbes $\mathrm{CB}$, Harmon AH. Buying into community supported agriculture: strategies for overcoming income barriers. J Hunger Environ Nutr. 2008;2:65-79.

16. Guthman J, Morris AW, Allen P. Squaring farm security and food security in two types of alternative food institutions. Rural Soc. 2006;7:662-684.

17. Cornell University. Dilmun-Hill student farm. Available at: http://hort.cals. cornell.edu/cals/hort/about/dilmun-hill/. Accessed January 13, 2009.

18. Center for Environmental Farming Systems. Workplace CSA. Available at: http:// www.cefs.ncsu.edu/rticsa.htm. Accessed January 13, 2009.

19. Michigan State University. Student organic farm. Available at: http://www. msuorganicfarm.org/home.php/. Accessed January 13, 2009.

20. University of California at Santa Cruz, Center for Agroecology and Sustainable Food Systems. Community outreach \& public service: community-supported agriculture program. Available at: http://casfs.ucsc.edu/community/csap.html. Accessed January 5, 2009.

21. American College \& University. Presidents climate commitment. Available at: http://www.presidentsclimatecommitment.org/. Accessed January 13, 2009.

22. Arizona State University. Bike co-op. Available at: http://www.asu.edu/tour/ sustainability/bikecoop.html. Accessed December 15, 2008.

23. Arizona State University Commuter Options. Zipcar. Available at: http:// uabf.asu.edu/parking_commuter_zipcar. Accessed December 15, 2008.

24. Montana State University. MSU's mission-Bozeman campus. Available at: http:// www.montana.edu/opa/policy/MissionBozeman.html. Accessed December 15, 2008. 
25. Montana State University. Towne's harvest garden. Available at: http://www. townesharvest.montana.edu. Accessed December 15, 2008.

26. Arizona Local Food. The local organic food connection! Available at: http:// www.arizonalocalfood.com/. Accessed December 15, 2008.

27. Arizona State University. PolyHarvest CSA. Available at: http://www. polycsa.org. Accessed December 15, 2008.

28. Community Alliance with Family Farmers. Building local food programs on college campus. Available at: http://www.caff.org/publications/. Accessed January 13, 2009. 